\title{
Trends in intensive care in patients over 90 years of age
}

This article was published in the following Dove Press journal:

Clinical Interventions in Aging

5 September 2012

Number of times this article has been viewed

\section{Josef Yayan}

Department of Internal Medicine, Vinzentius Hospital, Landau, Germany
Correspondence: Josef Yayan

Department of Internal Medicine, Vinzentius Hospital, Cornichonstraße 4

D-76829, Landau, Germany

Tel +49634 II 6128

Fax +49634 II4 2254

Email josef.yayan@hotmail.com
Background: Average life expectancy has increased over the past century, leading to a larger proportion of elderly in the population. Comorbidity and dependence increases with age, and recent data have shown that the number of elderly patients admitted to intensive care is increasing. This has implications for the availability of health care for these patients, as health care is a finite resource.

Objective: This study examines the demographics of patients aged over 90 years who were admitted into the medical intensive care unit, in order to verify the results of previous research.

Methods: From 2007 to 2011, a retrospective study was conducted in very elderly patients (over 90 years of age) and elderly patients (between 80 and 89 years of age) admitted into intensive care in Vinzentius Hospital, a medium-size, acute-care, general hospital in Landau, Germany.

Results: A total of 8554 intensive care treatments were carried out in the study period. The number of intensive care treatments performed on patients aged over 90 years and those aged 80 to 89 years was $212(2.48 \%)$ and 1715 (20.05\%), respectively. No increase in the number of medical intensive care treatments was observed in very elderly patients over this period.

Conclusion: Compared to the results of previous studies, an increase in the number of medical treatments in the intensive care units of patients aged over 90 years over the study period could not be found.

Keywords: very elderly patients, medical intensive care setting, medical emergency diseases

\section{Introduction}

Average life expectancy has increased over the past century, resulting in a shift in world population demographics. Indeed, the number of elderly people is at its highest in human history. Previous research by McDermid and Bagshaw ${ }^{1}$ showed that comorbidity and dependency independently predicted mortality, and the need for hospitalization and institutionalization. As both comorbidity and dependency increase with age, more elderly people are living longer in more tenuous states of health. The proportion of elderly patients admitted to the hospital and intensive care is considerable compared with the general population, and data from the McDermid and Bagshaw study suggest an increasing trend in elderly admissions. A previously published study has shown that elderly patients often receive less intensive therapy and face greater support limitations when admitted to intensive care, implying that there may be a selection bias among elderly patients triaged for access to finite critical care. ${ }^{1}$ This may be due to the consumption of a disproportionate amount of the total intensive care unit (ICU), and total hospital, direct cost by the relatively small number of patients who require prolonged intensive care. ${ }^{2}$ 
Most patients with an acute critical illness lack the capacity to make decisions about life-support treatments. ${ }^{3,4}$ Indeed, the majority of ICU deaths are preceded by such decisions, which may be based on documented pretreatment preferences regarding life-sustaining treatments that were previously expressed by the patient (as an advance directive), or the judgment of an appropriate surrogate decision maker, including a legally appointed, health-care proxy. ${ }^{3,4}$

Against this background, this study aimed to evaluate the trends in intensive care treatment of very elderly patients. Specifically, this study attempted to verify whether there is an increase in intensive care treatments of the very elderly.

\section{Methods \\ Study groups}

A retrospective study was conducted on patients admitted into intensive care in the Department of Internal Medicine and the Department of Anesthesia, Intensive Care and Pain Management in the 400-bed Vinzentius-Hospital in Landau, Germany, from 2007 to 2011. The patients in the study group consisted of the very elderly (aged 90 and above) who were admitted into intensive care. These patients were compared against those between 80 and 89 years of age (control group) who were admitted into intensive care. All patients with primary internal diseases referred by family doctors, the emergency service center, and other medical departments were sampled.

\section{Variables}

The demographics of both groups, such as age, sex, and reason for admission, were compared. Any secondary acute illnesses of the patients were grouped together according to organ systems, and compared. The cardiovascular risk factors examined were elevated blood pressure, diabetes mellitus, hyperlipidemia, obesity, smoking, and a family history of cardiovascular disease. Differences in comorbidities and length of stay in the ICU were also investigated. A major adverse cardiac event (MACE) was defined as the occurrence of death, a previous history of stroke, or myocardial infarction. The declaration of intent by all patients was considered prior to treatment in intensive care. If there was a written advance directive provided, the legal representative was again asked about the treatment in the intensive care units. For patients who were incapable of making a decision due to disease, a written request for the exhibition of an advance directive was made at the district court, after contacting a close family member. In cases of doubt, it was assumed that the patients would receive the full treatment in intensive care. The patients who refused treatment in the ICU, received full medical therapy in the general wards of the Department of Internal Medicine.

\section{Statistical analysis}

The Chi-square test was used to make comparisons among variables such as gender, intensive care treatments, treatments conducted in the general wards of the internal departments of the hospital, medical emergency diseases, acute illnesses, cardiovascular risk factors, comorbidities, and MACE. The Mann-Whitney $U$ test was used to calculate differences between the two groups in terms of the total number of intensive care treatments, length of stay in the ICU, total number of internal emergency diseases, acute illnesses, comorbidities, cardiovascular risk factors, and MACE. The confidence interval (CI) of a proportion was calculated as well. The survival rate for both groups was calculated using the Kaplan-Maier method. The data were checked for normality using the Kolmogorov-Smirnov test. A $P$ value $<0.05$ was considered statistically significant. Results involving the mean and standard deviation (SD) are shown as "mean (SD)."

\section{Results}

\section{Intensive care treatments}

A total of 8554 patients were sampled over the 5-year period, of whom 212 (2.48\%) (95\% CI, $\pm 0.33 \%, 2.15 \%-2.81 \%)$ were in the study group and 1715 (20.05\%) (95\% CI, $\pm 0.85 \%$, $19.2 \%-20.9 \%)$ in the control group. A significant difference was found in the number of intensive care treatments between the two groups $(P<0.001)$. As shown in Figure 1, the number of patients in both groups undergoing intensive care treatment remained relatively stable over the 5-year period, although a significant decline was observed in both groups in 2011. The number of people in the control group who received intensive care was consistently higher than that in the study group $(\mathrm{n}=1539): 35(2.27 \%)$ in the study group and 291 (18.91\%) in the control group, in 2011.

\section{Intensive care settings}

The number of patients who received intensive care in the Department of Internal Medicine was 146 for the study group and 1121 in the control group, while the number of patients who received intensive care from the Department of Anesthesiology was 66 in the study group and 641 in the control group. A Chi-square test found no significant difference between the two medical settings in both groups $(P=0.13)$ (Figure 2). 


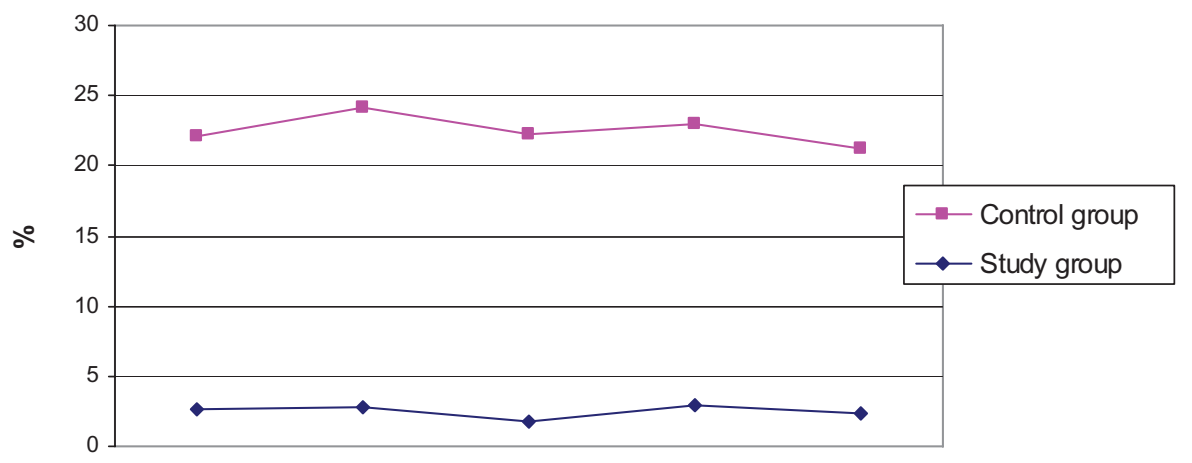

Years 2007-2011

Figure I Number of cases admitted into intensive care for both groups from 2007-20 I .

\section{General wards of the Department of Internal Medicine}

The general wards of the Department of Internal Medicine treated $(\mathrm{N}=20,996), 654$ (3.11\%) patients in the study group and 4968 (23.66\%) from the control group during the 5 -year period. There was a significant difference of hospital environment in both groups $(P<0.0001)$; in other words, the type of ward that the patient was in (intensive care or general ward) significantly differed between the two groups (Figure 3).

\section{Age and gender distribution}

The mean age of all patients treated in intensive care was $66.41(\mathrm{SD}=17.90)$ years, with the median and mode ages being 71 and 78 years, respectively. The mean ages of the study and control groups was $92.7(\mathrm{SD}=6.98)$ and 83.84 $(\mathrm{SD}=2.56)$ years, respectively. The median and mode ages in the study group were 92 and 91, respectively, and the median and mode ages in the control group were 84 and 81 , respectively. The oldest patients (a man and a woman) were both aged 103. There was a significant difference for gender in treatment in intensive care $(P<0.0011)$, with more

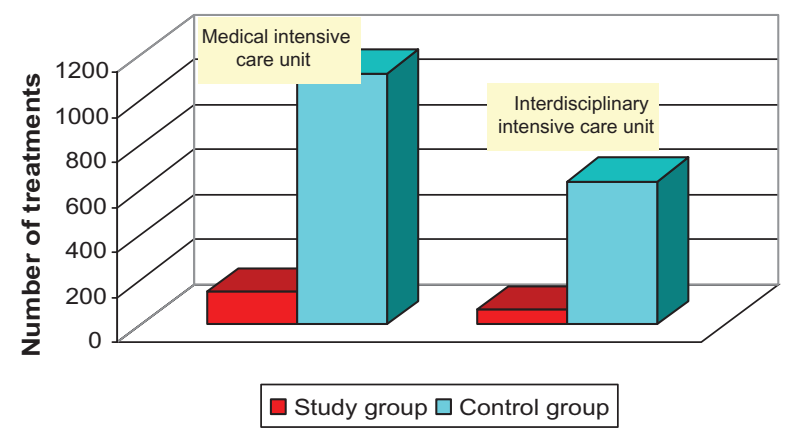

Figure 2 Intensive care settings: the number of treatments on the medical intensive care unit and interdisciplinary intensive care unit of the department of anesthesiology. women than men receiving intensive care in both groups (Figure 4).

\section{Medical emergency diseases in the intensive care units}

The two groups differed significantly in the total number of medical emergencies diagnosed $(P<0.001)$, with more patients in the control group having a medical emergency than in the study group. However, a breakdown of the medical emergencies showed that significant differences between the two groups existed only in two types of emergencies cardiogenic pulmonary edema $(P=0.01)$ and acute respiratory failure $(P=0.02)$ - with a higher proportion of patients in the study group treated for both of these emergencies compared with the control group. Acute respiratory failure and myocardial infarction were the most frequently occurring events for both groups (Table 1).

\section{Acute illnesses}

A significant difference was found between the two groups in the total number of acute illnesses $(P<0.01)$, with a larger number of patients in the control group being diagnosed with an acute illness than in the study group. A breakdown of the various acute illnesses revealed a significant difference between the two groups in thyroid illnesses $(P=0.046)$, nervous system disorders $(P=0.037)$, orthopedic conditions $(P<0.01)$, and bone fractures $(P<0.01)$. Cardiovascular and gastrointestinal diseases were diagnosed the most frequently for both groups (Table 2).

\section{Cardiovascular risk factors}

The two study groups did not differ significantly in cardiovascular risk factors $(P=0.095)$. However, a breakdown of the risk factors found significant differences for each of the risk factors except nicotine habit (hypertension: $P<0.01$; 


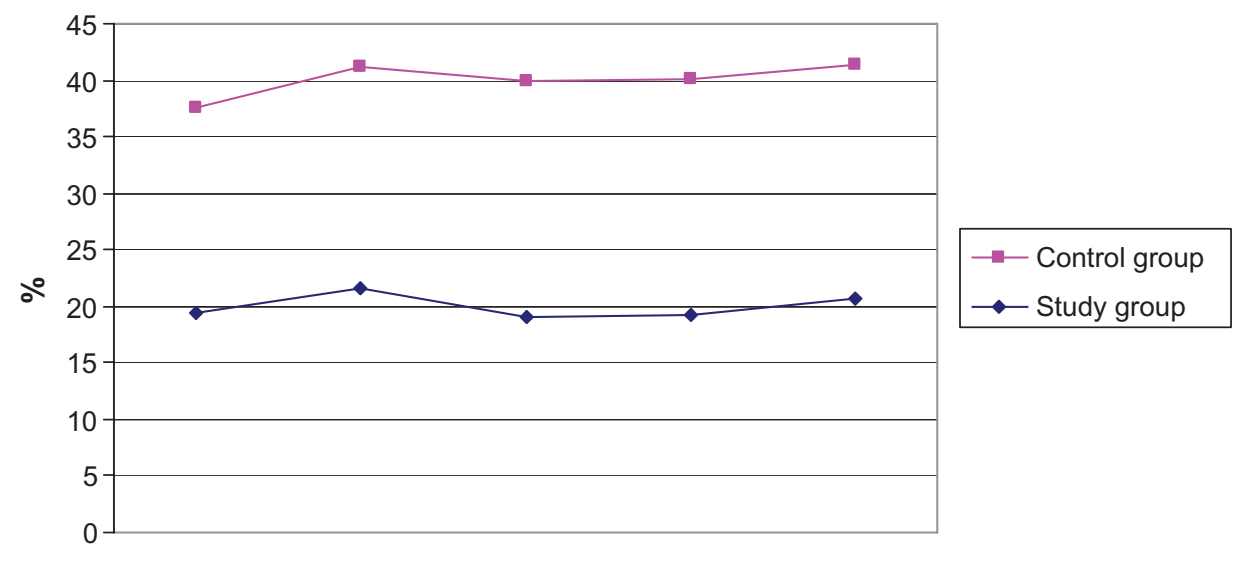

Years 2007-2011

Figure 3 The number of treatments on the general wards of the internal departments in the study group and the control group, from 2007-20II.

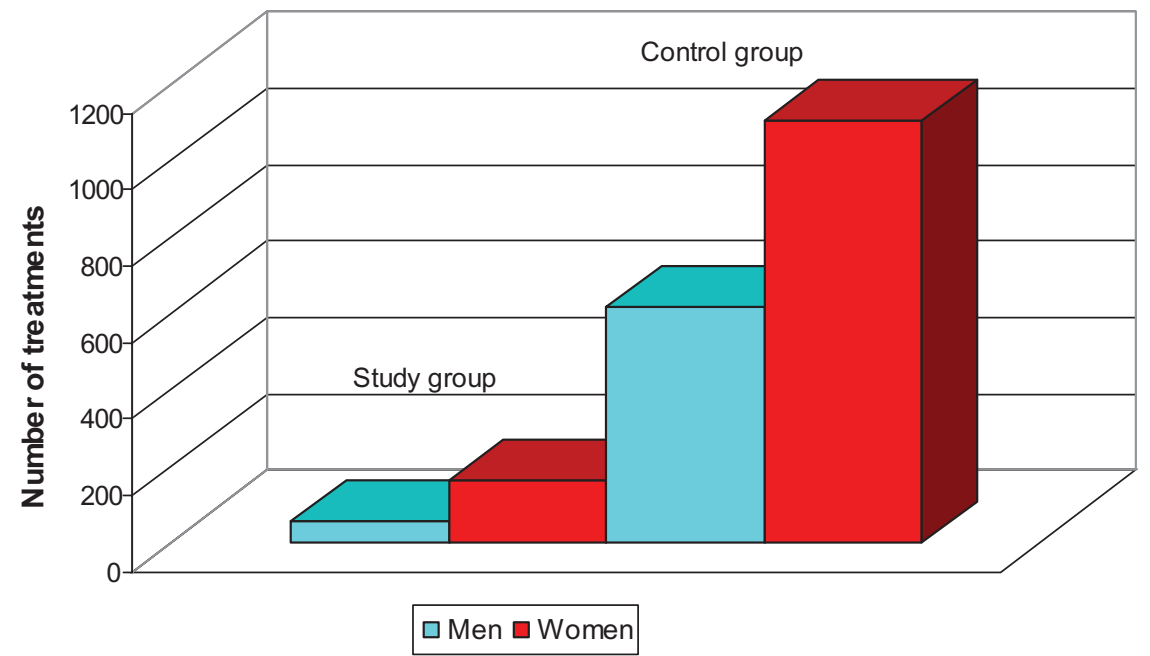

Figure 4 Gender distribution in the intensive care units.

Table I Number of medical cases admitted into intensive care by type

\begin{tabular}{|c|c|c|c|c|}
\hline \multirow[t]{2}{*}{ Medical cases } & \multicolumn{2}{|c|}{ Number of cases } & \multirow{2}{*}{$\begin{array}{l}\text { Number of cases } \% \\
\text { Study group }(n=228) / \\
\text { Control group }(n=1565)\end{array}$} & \multirow[t]{2}{*}{$P$-value } \\
\hline & $\begin{array}{l}\text { Study group } \\
(n=2 \mid 2)\end{array}$ & $\begin{array}{l}\text { Control group } \\
(n=|7| 5)\end{array}$ & & \\
\hline Acute coronary syndrome & 16 & 152 & 7.02/9.7I & 0.52 \\
\hline Myocardial infarction & 43 & 303 & $18.86 / 19.36$ & 0.35 \\
\hline Shock & 11 & 71 & $4.82 / 4.54$ & 0.48 \\
\hline Syncope & 6 & 76 & $2.63 / 4.86$ & 0.28 \\
\hline Hypertensive crisis & 10 & 47 & $4.39 / 3.00$ & 0.11 \\
\hline Cardiogenic pulmonary edema & 27 & $13 \mid$ & I I.84/8.37 & $<0.01$ \\
\hline Septic shock & 13 & 80 & $5.70 / 5.11$ & 0.35 \\
\hline Acute respiratory failure & 57 & 345 & $25.00 / 22.04$ & 0.02 \\
\hline Pulmonary embolism & 2 & 30 & $0.88 / 1.92$ & 0.32 \\
\hline Decompensated cor pulmonale & 4 & 19 & $1.75 / I .21$ & 0.37 \\
\hline Severe infectious disease & 10 & 77 & $4.39 / 4.92$ & 0.88 \\
\hline Intoxication & 2 & 13 & $0.88 / 0.83$ & 0.77 \\
\hline Gastrointestinal bleeding & 11 & 61 & $4.82 / 3.90$ & 0.24 \\
\hline Epileptic attack & 1 & 36 & $0.44 / 2.30$ & 0.10 \\
\hline Acute stroke & 15 & 124 & $6.58 / 7.92$ & 0.93 \\
\hline Total cases $(n=1793)$ & 228 & 1565 & I 2.72/87.28 & $<0.001$ \\
\hline
\end{tabular}




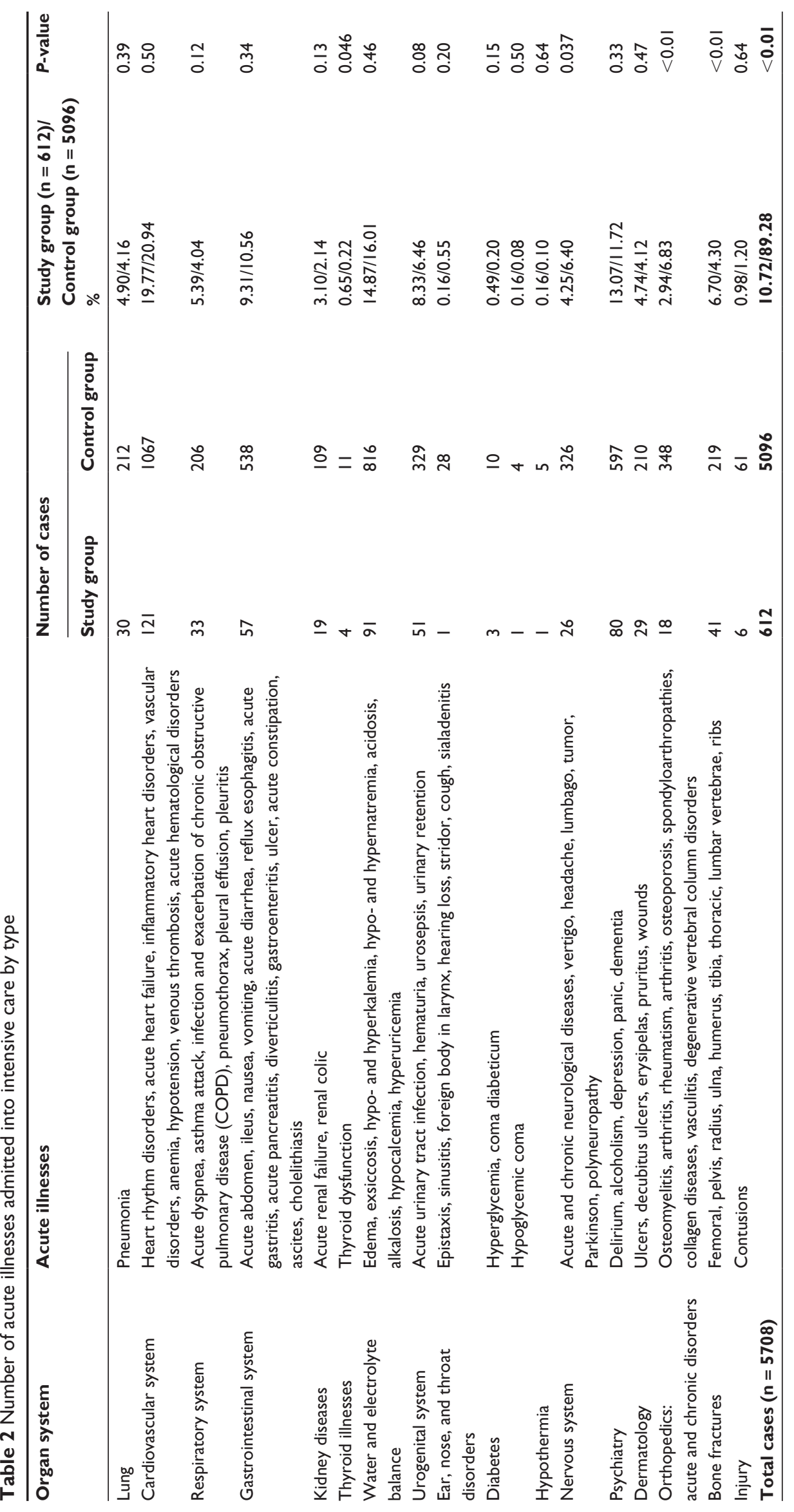


diabetes: $P<0.01$; hyperlipidemia: $P<0.01$; obesity: $P<0.01$ ) (Table 3).

\section{Length of stay in the intensive care unit}

The average length of stay in the intensive care units was 4.73 $(\mathrm{SD}=5.39)$ days in the study group and $5.68(\mathrm{SD}=6.80)$ days in the control group. The Kolmogorov-Smirnov test showed that the normal distribution in the study and control groups was 70.339 and 589.956, respectively, with a significant deviation of at least $99 \%$ from a normal distribution. The length of the stay in the intensive care units did not differ significantly between the groups $(P=0.21)$.

\section{Comorbidities}

As shown in Table 4, the two groups differed significantly in comorbidities $(P<0.01)$, with more people in the control group having comorbidities compared with the study group. Significant differences between the two groups in the type of comorbidities present were also found (tumors: $P<0.01$; thyroid disorders: $P<0.01$; chronic ear, nose, and throat disorders: $P=0.03$; ophthalmic disorders: $P=0.03$ ). A higher proportion of patients in the study group had chronic ear, nose, and throat disorders and ophthalmic disorders as comorbid diseases than in the control group, whereas the proportion of people in the control group with tumors and thyroid disorders as comorbid diseases was higher than the study group. The most common comorbidities were disorders of the cardiovascular, renal, and gastrointestinal systems.

\section{Major adverse cardiac event}

In the study group, 10 patients $(4.72 \%)$ had a history of stroke, while this number was 124 (7.23\%) for the control group. There was no significant difference in this between the two groups $(P=0.175)$. The survival rate calculated using the Kaplan-Maier method for the 212 patients in the study group, where $3(1.42 \%)$ deaths occurred, was $98.58 \%$ (95\% CI, 96.98\%-100\%), while the calculated survival rate for patients in the control group, where $44(2.57 \%)$ deaths occurred, was $97.43 \%$ (95\% CI, 96.67\%-98.19\%). There was no significant difference between the two groups in the number of deaths $(P=0.31)$.

\section{Discussion}

The increase in the proportion of elderly in the population has increased the demand for health care. Previous studies have shown that the number of patients aged 80 years and older admitted to the ICU has increased during the past decade, as has the intensity of the care for these patients. ${ }^{5}$ However, this study did not find an increase in the admissions of the elderly to the ICU. Indeed, significantly more patients (around 8 times as many), who were at least 10 years younger, were treated in the ICU. The failure to replicate the results of previous studies may be due to a number of reasons, such as life expectancy, the number of hospitals and available facilities for the elderly in the vicinity, and the existence of a geriatric department in the hospital. In the town where this study was conducted, there is another similar hospital. Facilities for elderly patients are available as well. For example, the hospital studied organizes the home care of single needy elderly before discharge. In addition, nursing homes for geriatric rehabilitation and even round-the-clock nurses are available, and could be hired to look after the patient at home. Furthermore, while this hospital lacks a geriatric department, clinics with geriatric departments are available in neighboring cities. These factors could have affected the size and parameters of the population in this study.

This study is also inconsistent with previous studies with regard to the gender distribution of patients treated in intensive care. While previous studies observed that men appear to be admitted more frequently than women among

Table 3 Number of cardiovascular risk factors in both groups by type

\begin{tabular}{|c|c|c|c|c|}
\hline \multirow[t]{4}{*}{ CVRF } & \multirow{4}{*}{$\begin{array}{l}\text { Study group } \\
(n=2 \mid 2)\end{array}$} & \multirow{4}{*}{$\begin{array}{l}\text { Control group } \\
(n=17 \mid 5)\end{array}$} & Number of cases & \multirow[t]{4}{*}{$P$-value } \\
\hline & & & Study group $(n=158) /$ & \\
\hline & & & Control group $(n=1864)$ & \\
\hline & & & $\%$ & \\
\hline Hypertension & 93 & 932 & $58.86 / 50.00$ & $<0.01$ \\
\hline Diabetes & 45 & 574 & $28.48 / 30.79$ & $<0.01$ \\
\hline Hyperlipidemia & 18 & 264 & $11.39 / 14.16$ & $<0.01$ \\
\hline Obesity & 2 & 85 & $1.27 / 4.56$ & $<0.01$ \\
\hline Nicotine habit & 0 & 9 & $0.00 / 0.48$ & 0.29 \\
\hline Total cases $(n=2022)$ & 158 & 1864 & $7.81 / 92.19$ & 0.095 \\
\hline
\end{tabular}

Abbreviation: CVRF, cardiovascular risk factors. 


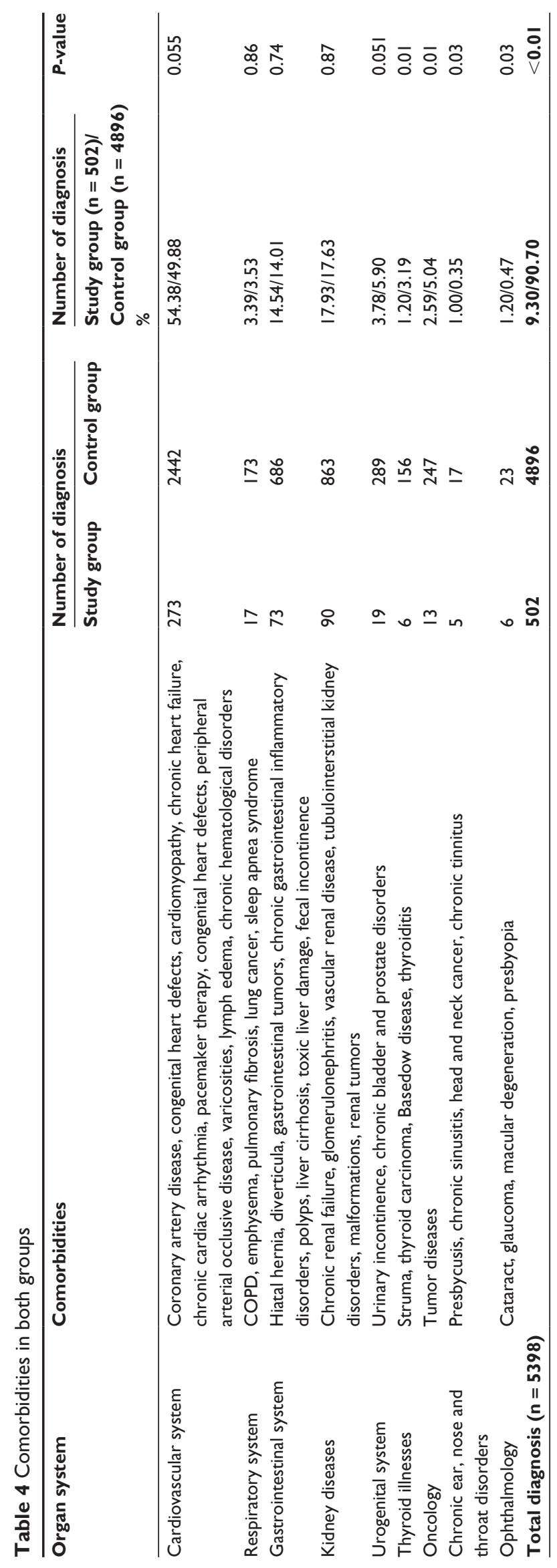

the elderly, ${ }^{6,7}$ the present study found that women were treated in intensive care more often than men, in both the study group and the control group. Although this does not correspond with most previous studies, the study conducted by Ngyuen et $\mathrm{al}^{8}$ provides a possible explanation for the current findings. The authors reviewed factors associated with prehospital delay in patients with acute myocardial infarction and found that women tended to delay seeking medical attention after developing possible symptoms. As delaying treatment increases the severity of the disease, and myocardial infarction was a frequently cited reason for hospital stay in the present study, this may have led to the current finding of more women being admitted to intensive care than men.

Discrepancies also exist between the young and the old in terms of delay of treatments and use of recommended guidelines. In a large review of elderly patients over 65 years who suffered from acute myocardial infarction, Nguyen et a ${ }^{8}$ reported that the elderly were more likely to have a longer prehospital delay than were younger patients. Although myocardial infarction was the second most predominant reason for intensive care admission in the present study, participants in the study group were still admitted less frequently than those in the control group. In contrast, the Nguyen et al study seems to imply that the very elderly were admitted more frequently than younger patients.

Intensive care admission criteria have traditionally included the severity of illness, comorbidities, the levels of frailty and disability, the expected impact of treatment on the outcome, the expression of wishes regarding do-not-resuscitate orders, and the availability of ICU beds. ${ }^{9}$ However, some data suggest that the presence of comorbidities and functional status may be poor predictors of outcome. In a large American cohort of elderly patients, Yende et al ${ }^{10}$ reported that prehospitalization comorbid conditions did not influence long-term mortality after pneumonia, although unplanned admission to the intensive care unit has been found to increase the risk of in-hospital mortality in very elderly patients. ${ }^{11}$ At least $50 \%$ of the risk of in-hospital death in this age group is attributable to a combination of unplanned admission and comorbidity with one or more disorders, such as acute renal failure and respiratory failure. ${ }^{11}$ This study found that the very elderly had no more comorbidities than the control group and that the survival rate of the very elderly was actually higher (although not significantly) than relatively younger patients. Even though the association between comorbidity and survival rate was not compared directly in this study, the results seem to imply that comorbidities do 
predict survival rate. Future studies could investigate the strength of the association between the different comorbidities and survival rates.

Recent data suggest that greater age and a high level of severity of illness are predictive of poor outcomes. Sligl et al ${ }^{12}$ reported that among critically ill adult patients with pneumonia, an age of 80 years and older was an independent predictor of death at 30 days, as well as one year. In this study, all patients, particularly those with pneumonia, with increasing respiratory failure or another indication for intubation, were transferred to the interdisciplinary intensive care setting for intubation. In the study group of the present study, one man and one woman $(0.94 \%)$ died from pneumonia while nine men and seven women $(0.93 \%)$ died from pneumonia in the control group. The survival rate for patients with pneumonia was slightly worse in the study group (99.06\%) compared with the control group (99.07\%) in the present study. The mortality rate for pneumonia was better in both groups in this study, than in the Sligl study.

This study observed that a relatively large number of the patients in the ICU had sepsis. Iwashyna et $\mathrm{al}^{13}$ demonstrated that severe sepsis was associated with cognitive impairment and functional disability, and severe sepsis patients exhibited a sharp decline in health-related quality of life during their intensive care stay followed by a gradual improvement during the 6 months after intensive care unit discharge, ${ }^{14}$ with recovery beginning after discharge from the ICU to the general ward. Nevertheless, recovery in physical functioning and general health dimensions at 6 months after intensive care unit discharge was incomplete, compared with preadmission status. ${ }^{14}$ Future studies could examine the outcome after admission to, or discharge from, the ICU, in terms of recovery instead of survival rate.

Injuries and illnesses leading to hospitalizations are associated with increased disability and reduced recovery. ${ }^{15}$ Indeed, in one study, a high mortality rate and a decrease in quality of life were observed in elderly patients with severe abdominal pathologies, although they were able to adapt well to their physical disabilities. ${ }^{16}$ The present study found that a large number of patients were admitted to the ICU because of gastrointestinal hemorrhage and acute pancreatitis. Although no investigation was conducted to determine changes in their levels of disabilities or quality of life, future studies could explore this aspect and verify the results of previous studies.

Yu et $\mathrm{al}^{17}$ found that the likelihood of an admission into the ICU among the elderly actually decreased with age, especially among those 85 years or older, with a great majority of them surviving at least 90 days. ${ }^{17}$ The authors suggested that the diagnostic mix is an important influence on ICU use by age. ${ }^{17}$ This is also a possible explanation for the failure to reveal an association between age and ICU admission in the present study. Future studies could investigate the effect of diagnostic mix on ICU admissions by age.

\section{Conclusion}

The author did not observe an increase in the number of intensive care treatments of very elderly patients in the medical intensive care settings of the hospital studied in recent years. Indeed, the number of very elderly patients admitted into intensive care was lower than the number of patients who are relatively younger. The very elderly were also found to have less acute illnesses and comorbidities than relatively younger patients. In addition, more women than men were found to have received intensive care in both groups during the period in which this study was conducted.

\section{Disclosure statement}

The author reports no conflicts of interest.

\section{References}

1. McDermid RC, Bagshaw SM. ICU and critical care outreach for the elderly. Best Pract Res Clin Anaesthesiol. 2011;25(3):439-449.

2. Bashour CA, Yared JP, Ryan TA, et al. Long-term survival and functional capacity in cardiac surgery patients after prolonged intensive care. Crit Care Med. 2000;28(12):3847-3853.

3. Camhi SL, Mercado AF, Morrison RS, et al. Deciding in the dark: advance directives and continuation of treatment in chronic critical illness. Crit Care Med. 2009;37(3):919-925.

4. Nicholas LH, Langa KM, Iwashyna TJ, Weir DR. Regional variation in the association between advance directives and end-of-life Medicare expenditures. JAMA. 2011;306(13):1447-1453.

5. Nguyen YL, Angus DC, Boumendil A, Guidet B. The challenge of admitting the very elderly to intensive care. Ann Intensive Care. 2011;1(1):29.

6. Fowler RA, Sabur N, Li P, et al. Sex-and age-based differences in the delivery and outcomes of critical care. CMAJ. 2007;177(12): 1513-1519.

7. Blomkalns AL, Chen AY, Hochman JS, et al; for CRUSADE Investigators. Gender disparities in the diagnosis and treatment of non-ST-segment elevation acute coronary syndromes: large-scale observations from the CRUSADE (Can Rapid Risk Stratification of Unstable Angina Patients Suppress Adverse Outcomes With Early Implementation of the American College of Cardiology/American Heart Association Guidelines) National Quality Improvement Initiative. J Am Coll Cardiol. 2005;45(6):832-837.

8. Nguyen HL, Saczynski JS, Gore JM, Goldberg RJ. Age and sex differences in duration of prehospital delay in patients with acute myocardial infarction: a systematic review. Circ Cardiovasc Qual Outcomes. 2010;3(1):82-92.

9. Boumendil A, Somme D, Garrouste-Orgeas M, Guidet B. Should elderly patients be admitted to the intensive care unit? Intensive Care Med. 2007;33(7):1252-1262.

10. Yende S, Angus DC, Ali IS, et al. Influence of comorbid conditions on long-term mortality after pneumonia in older people. J Am Geriatr Soc. 2007;55(4):518-525. 
11. Frost SA, Davidson PM, Alexandrou E, et al. Unplanned admission to the intensive care unit in the very elderly and risk of in-hospital mortality. Crit Care Resusc. 2010;12(3):171-176.

12. Sligl WI, Eurich DT, Marrie TJ, Majumdar SR. Age still matters: prognosticating short- and long-term mortality for critically ill patients with pneumonia. Crit Care Med. 2010;38(11):2126-2132.

13. Iwashyna TJ, Ely EW, Smith DM, Langa KM. Long-term cognitive impairment and functional disability among survivors of severe sepsis. JAMA. 2010;304(16):1787-1794.

14. Hofhuis JG, Spronk PE, van Stel HF, Schrijvers AJ, Rommes JH, Bakker J. The impact of severe sepsis on health-related quality of life: a long-term follow-up study. Anesth Analg. 2008;107(6):1957-1964.
15. Gill TM, Allore HG, Gahbauer EA, Murphy TE. Change in disability after hospitalization or restricted activity in older persons. JAMA. 2010;304(17):1919-1928.

16. Merlani P, Chenaud C, Mariotti N, Ricou B. Long-term outcome of elderly patients requiring intensive care admission for abdominal pathologies: survival and quality of life. Acta Anaesthesiol Scand. 2007;51(5):530-537.

17. Yu W, Ash AS, Levinsky NG, Moskowitz MA. Intensive care unit use and mortality in the elderly. J Gen Intern Med. 2000;15(2):97-102.
Clinical Interventions in Aging

\section{Publish your work in this journal}

Clinical Interventions in Aging is an international, peer-reviewed journal focusing on evidence-based reports on the value or lack thereof of treatments intended to prevent or delay the onset of maladaptive correlates of aging in human beings. This journal is indexed on PubMed Central, MedLine, the American Chemical Society's 'Chemical Abstracts Ser-

\section{Dovepress}

vice' (CAS), Scopus and the Elsevier Bibliographic databases. The manuscript management system is completely online and includes a very quick and fair peer-review system, which is all easy to use. Visit http://www.dovepress.com/testimonials.php to read real quotes from published authors.

Submit your manuscript here: http://www.dovepress.com/clinical-interventions-in-aging-journal 